\title{
Las crónicas de Indias: testimonios de verdad de un nuevo mundo sobrenatural
}

\author{
VANINA M. TEGLIA \\ Universidad de Buenos Aires \\ ILH/CONICET \\ vaninateglia@filo.uba.ar
}

Recibido: 30/10/2021 - Aceptado: 15/11/2021

DOI: https://doi.org/10.46553/LET.84.2021.p58-76

Resumen: Este artículo revisa las caracterizaciones que, desde la crítica y la bibliografía académica, han recibido las crónicas de Indias en sus semejanzas y diferencias con la crónica occidental -y con la española específicamente-, vinculadas desde sus orígenes con el poder gobernante. Propongo que este género discursivo, que proliferó entre los documentos de Indias, dio lugar oportunamente entre sus páginas al testimonio de un mundo que, desde la lejanía, se esperaba que fuera vencido por los hombres enviados a conquistar y colonizar el continente. Las crónicas de Indias se propusieron a sí mismas como testimonios de vista de un mundo desaparecido y, a la vez, esperanzador, nuevo y deseable. Cuestiono, además, el efecto de verdad de la reiteración gramatical del enunciador en primera persona de estos textos (el yo) para poner el acento, en cambio, en sus posibilidades discursivas de certificación del propio sujeto. Por último, propongo que, como en espejo, las visiones del testigo de vista están constituidas por algo conocido y algo nuevo a la vez; codificadas por tradiciones, pero también transformadas por el contexto transatlántico. En esto, lo maravilloso -lo novedoso sobrenatural indiano - jugó un rol fundamental, incluso, en sus formas amenazantes y perturbadoras, ajenas a lo milagroso y hasta a lo demoníaco.

Palabras clave: crónicas de Indias - testimonio - Nuevo Mundo - testigo de vista -lo maravilloso

\section{The chronicles of the Indies: testimonies of truth of a new supernatural world}

\begin{abstract}
This article reviews the characterizations that, from criticism and academic bibliography, have received the chronicles of the Indies in their similarities and differences with the western chronicle -and with the Spanish one specifically-, linked from their origins with the ruling power. I propose that this discursive genre, which proliferated among the documents of the Indies, opportunely gave place among its pages to the testimony of a world that, from afar, was expected to be conquered by the men sent to conquer and colonize the continent. The chronicles of the Indies proposed themselves as testimonies of a vanished world and, at the same time, hopeful, new and desirable. I also question the truth effect of the grammatical reiteration of the first-person enunciator in these texts (the "I") to emphasize, instead, their discursive
\end{abstract}


possibilities of certifying the subject itself. Finally, I propose that, as in mirror, the visions of the eyewitness are constituted by something known and something new at the same time; encoded by traditions, but also transformed by the transatlantic context. In this, the marvelous -the supernatural Indian novelty- played a fundamental role, even in its threatening and disturbing forms, alien to the miraculous and even to the demonic.

Key words: chronicles of the Indies, testimony, New World, eyewitness, the marvelous.

\section{Testimonios de viaje}

Llegados al punto del avance actual de los estudios coloniales, nos preguntamos por qué, entre los documentos relativos a lo sucedido con las conquistas y la colonización española -y otras europeas - en América, el género discursivo que más destacó y el más (re)leído sobre los asuntos de Indias ha sido la crónica. Nos preguntamos qué hizo que ella resultara un género eficaz (Chang Rodríguez, 1982) para narrar el encuentro de culturas o la invasión de las Indias y para ofrecer una verdad "más apegada a los hechos" (González Echevarría, 1984, 161).

La crónica -y en esto seguimos a Hayden White (1992) en su análisis del relato de representación histórica-es superadora de los anales históricos, que consistían en aquellos calendarios de la Antigüedad referidos al pasado. De forma concisa y cronológica, los anales enumeraban los acontecimientos significativos de una comunidad, reino o nación sin conseguir configurar un componente narrativo. La crónica, en cambio, surgida en el Occidente medieval, se caracteriza por su coherencia narrativa, organización de los materiales por temas y, a veces, por ámbitos, aunque conserva el ordenamiento cronológico en el relato de los episodios, típico de los anales. Pero, a diferencia de la Historia -género posterior que alcanza su perfección en el Romanticismo--, fracasa en conseguir el cierre narrativo y -como concluye Whitesuele finalizar el relato simplemente con un desenlace abierto, al que podrían agregarse más episodios sobre el mismo tema en cualquier ocasión.

Un ejemplo paradigmático y considerado iniciador de las crónicas en el ámbito colonial indiano son los diarios de viaje de Cristóbal Colón. Si bien perdidos hoy, los diarios colombinos recuperados y resumidos por el fraile Bartolomé de las Casas refieren los eventos sucedidos al Almirante y a su armada desde su salida de Sevilla, en el cruce del Océano Atlántico, llegada a las Indias y retorno. Puesto que las distancias comienzan a tornarse un tema central en las crónicas de Indias, la realidad geográfica se impone sobre la escritura y compite por ser el eje vertebrador de los núcleos narrativos en estos relatos. Así es como algunas crónicas de Indias, como la Relación o Naufragios de Álvar Núñez Cabeza de Vaca, la Brevísima relación de la destrucción de las Indias, entre muchas otras, comienzan el relato guiadas por un claro eje temporal para organizar, luego, las unidades narrativas de acuerdo con los espacios recorridos e identificados.

El nombre "crónica" deriva del griego khronos ("el tiempo que pasa"), aunque algunas crónicas consideran que, etimológicamente, la palabra ha derivado de "corona", 
por su relato de los hechos de los reinos medievales y renacentistas y por una deformación lingüística del nombre que, por momentos, deviene en "corónica". Sin embargo, esta segunda interpretación parece forzada y, en crónicas de Indias, solo la he visto cuando, con el estilo propio de la filología renacentista, se intenta sumar una alabanza a la Corona en la captatio benevolentiae de los paratextos. Es por este mismo motivo que la Primer nueva corónica y buen gobierno de Guamán Poma de Ayala advierte en su "Consideración":

Se ha leído todas las historias y corónicas de los reyes principales emperadores del Mundo de los reyes y príncipes emperadores del Mundo, así cristianos como del gran turco y del rey chino, emperadores de Roma y de toda la cristiandad, y de judíos y del rey de Guinea, no he hallado a ninguno que haya sido tan gran majestad y sean menospreciados, y no ha sido tan gran majestad ni tan gran rey y de tan alta corona como mi abuelo rey Inca Yupanqui. (Huaman Poma de Ayala, 2015, 497-498)

La deformación de "crónica" en "corónica" y las asociaciones que despierta el término develan, en verdad, el vínculo cercano entre relato histórico y narración sobre el poder gobernante $o$, incluso, la consolidación de este último que el género facilita.

Leonardo Funes (Funes, 2008) observó la genealogía discursiva que hizo que la cronística de Isidoro de Sevilla fuera la que fijara el estilo propio de la crónica española. Además de haber reunido ideológicamente a los pueblos hispánicos bajo el concepto de un poder central, el estilo narrativo isidoriano hereda, de los anales históricos, la escansión temporal de la que -como vimos-las crónicas de Indias son continuadoras. Además, este estilo agrega un componente estructurante: "el del personaje-protagonista (emperador, rey, obispo), herencia de la narración hagiográfica" (Funes, 2008, 246). En este sentido, las crónicas de Indias, así como las relaciones de méritos y servicios, se esfuerzan enormemente por configurar un ethos heroico, merecedor de famas, pero, sobre todo, de distinciones nobiliarias para las familias involucradas y réditos económicos. Sobre esta cuestión, las cartas de relación de Hernán Cortés son un modelo temprano y rector de otras crónicas de Indias, sobre todo, porque México constituyó la primera conquista que interesó a la Corona española y porque Francisco López de Gómara, Cronista Oficial en España, entronó la versión cortesiana de los hechos como la "verdadera" historia de la conquista de México.

Pero es el modelo creado por el rey español Alfonso X -poética del relato histórico vigente hasta el siglo XVI - el que instala la idea de la escritura historiográfica en prosa, más racional y ordenadora que el verso por su carencia de ornamentación. Esta cronística, además, construye al protagonista y a sus personajes especulares sobre el modelo de la figura ejemplar, mientras que, al narrador, le atribuye todos los poderes de la omnisciencia y la articulación de otras voces o fuentes, incluso, controvertidas o contradictorias, que son homogeneizadas por un principio de autoridad historiográfica. La crónica de Indias, por supuesto, se inserta en esta tradición genérica, pero amplía el espectro genérico incluyendo variedades sub-genéricas como las relaciones legales, las cartas relatorias, los diarios de viaje y de navegación, algunos géneros históricos particulares como las décadas, los comentarios y la historia de estructura profética, y las crónicas propiamente dichas desde ya, entre otros. 
En un artículo inaugural de 1982, Walter Mignolo consideró, a las crónicas de Indias, como una familia textual por su diversidad de formas y de funciones. Desde una mirada pragmática y semiótica, concluyó que lo común de este inmenso acervo, notorio en el archivo de documentos sobre las Indias, es su función de comunicación a la distancia como servicio a los reyes y en respuesta a sus pedidos oficiales. ${ }^{1}$ Es decir que estas crónicas-mensajes proliferaron, en el proceso de conquista y colonización, obligadas, a pesar de su variedad, por su función común de comunicar y suplir la distancia entre los hechos referidos, el espacio descripto y el poder imperial. Esta función, luego, se diversificó en otras en la escritura colonial, como la de guardar la memoria de los hechos (función que hizo valer el cronista oficial Gonzalo Fernández de Oviedo, por ejemplo) y/o referir la verdad de los hechos frente a las historias "mentirosas" (que asumió Bartolomé de las Casas, por ejemplo), entre otras.

Para Roberto González Echevarría, la Historia de corte humanístico: "da más importancia a la moral cortesana o caballeresca de los actores [...] se ocupaba de los momentos culminantes." (González Echevarría, 1984, 159 y 162). En cambio, las relaciones son informes legales en los que, generalmente, testigos oculares de los hechos dan cuenta de su desempeño o del de las personas circundantes: "se reflejaba en ellas, mediante ciertas fórmulas, el contacto de un yo con la realidad circundante" (González Echevarría, 1984, 160) y, por esto, engendrarían una verdad mejor avenida con los hechos. La relación daría cuenta de una verdad más contingente, más apegada a los hechos, "tal como éstos ocurrieron"; es decir, tal y como éstos le ocurrieron en el pasado al narrador. Esto explicaría, por ejemplo, la repetición de "yos" en la Historia verdadera de la conquista de la Nueva España de Bernal Díaz del Castillo, pero, también agregamos, en la Carta de Jamaica o Lettera Raríssima de Cristóbal Colón, que narra las peripecias e infortunios de su cuarto viaje a las Indias. Las recurrentes marcas del yo enunciador se aparecen como recurso de una verdad enfrentada a la de la historiografía humanística y a la oficial.

Ambas propuestas, la de Mignolo y la de González Echevarría, fueron muy consultadas y referidas por los Estudios coloniales de aquellos años y los posteriores. Sin embargo, a nuestro parecer y a la luz de los avances de los últimos años, consideramos que contienen, por lo menos, una visión en parte limitada e incompleta de la complejidad de la cronística de Indias (la de Mignolo) o de comprobación imposible (la de González Echevarría). ${ }^{2}$ Respondemos que las crónicas de Indias proliferaron entre los documentos de conquista y colonización no porque resultaran más comunicantes que otros géneros sino que resultaban más adecuadas para comunicar las expectativas del

\footnotetext{
1 "Estas cartas, que tienden más hacia lo documental que hacia lo textual, son portadoras de mensajes, que no son relatos de los descubrimientos o de las conquistas [...] sino comunicaciones (informes, solicitudes) que reemplazan la inevitable falta de copresencia entre el destinador y el destinatario" (Mignolo, 1982, 59)

${ }^{2}$ Sin embargo, en Mito y archivo (1998), González Echevarría se revisa y orienta sus planteos hacia ideas similares a las que proponemos en este trabajo. Por ejemplo, en la idea que sobrevuela todo su libro acerca de que la temprana historiografía de Indias se hallaba muy impregnada por la retórica legal.
} 
poder metropolitano. Por otro lado, dada la esencial arbitrariedad del lenguaje, no existe manera de comprobar que cualquier documento, así sea una crónica, una Historia o un poema, pueda reflejar más una verdad que otros géneros (¿por medio de qué convenciones en realidad?) o que tuviera la capacidad de hallarse "más apegado" a los hechos tal y como ocurrieron (sic).

Creemos, en cambio, que este efecto de verdad y calidad de más "comunicante" se explica en las convenciones del discurso legal de la época, que respondían a fórmulas fijadas o convenciones fijadas por el poder. Entre ellas: el testigo de vista (que trataremos adelante), el testimonio de lo vivido por un individuo, la ordenación cronológica, las referencias (los nombres) geográfico-espaciales, el responder a los intereses explícitos del Estado (considerando los pedidos de los cuestionarios confeccionados por la Corona), el dar lugar al relato de la dominación y a las batallas de conquista (tradicionalmente, la crónica, junto con la épica, era el género que narraba la conformación y entronamiento del héroe) y, entre otros, la opacidad del discurso legal, a pesar de que en su superficie simule una transparencia comunicativa. La relación legal y, más ampliamente, la crónica de fechos es un género que, de manera cronológica, pudo dar cuenta de los hechos de la conquista americana en la forma de testimonios, principalmente, del enunciador. De esta manera, los cronistas se presentan como testigos de vista o testigos de los testimonios de los hechos. No hay otra razón por la que, en 1532, la Corona ordena, al cronista Oficial de Indias, Fernández de Oviedo, asentarse en Santo Domingo de la Isla Española (Haití/República Dominicana) y escribir desde las Indias y no desde España la Crónica de la Conquista.

En cuanto al contenido, las crónicas no solo son testimonio de las gestas heroicas en tierras lejanas sino que su otra cara es ser testimonio del triunfo sobre una comunidad, pueblo o cultura. Siguiendo las teorizaciones de Giorgio Agamben (2019) sobre la cuestión del testimonio, observamos que, en su esencia, éste siempre describe al hombre que ha desaparecido y que ya no puede testimoniar por sí mismo. En los documentos de Auschwitz, Agamben observa que el testimonio siempre es un discurso del sobreviviente que refiere a Otro que no ha podido sobrevivir. ${ }^{3}$ En crónicas de Indias, observo una sutil pero significante diferencia: estos textos reúnen los testimonios de un enunciador que niega a los nativos americanos y a sus pueblos y que implícitamente declara que deben ser dejados atrás para dar lugar a un mundo nuevo. Las crónicas de Indias -sostenemos - contienen el mensaje que anuncia adánicamente un nuevo ciclo, un nuevo tiempo. Por esto, son tanto el testimonio de un mundo asesinado como el de uno que renace o que se piensa como nuevo.

Algunos títulos que autores y editores han elegido para estos textos son elocuentes sobre este punto: Mundus novus (1503) de Américo Vespucio, Primer viaje alrededor

\footnotetext{
${ }^{3}$ En palabras de Agamben: “Los 'verdaderos' testigos, los 'testigos integrales' son los que no han testimoniado ni hubieran podido hacerlo. Son los que 'han tocado fondo', los musulmanes, los hundidos. Los sobrevivientes, como pseudotestigos hablan en su lugar, por delegación, testimonian un testimonio faltante. [...] Quizás toda palabra, toda escritura nace, en este sentido, como testimonio. Por eso, aquello de lo que testimonia ya no puede ser lengua o escritura: solo puede ser un intestimoniado." (Agamben, 2019, 40 y 46)
} 
del Mundo (1524 y 1525) de Antonio Pigafetta, Brevísima relación de la destrucción de las Indias (1552), y otros títulos más sutiles como Crónica y relación copiosa y verdadera de los reinos de Chile (c. 1558) de Jerónimo de Vivar, Historia del Nuevo México (1611) de Gaspar de Villagrá o Argentina. Historia del descubrimiento y conquista del Río de la Plata (1612) de Ruy Díaz de Guzmán. Todas ellas refieren o suponen un mundo que muere y uno por construir que se inicia. ${ }^{4}$ También, por este motivo, las Indias fueron traducidas a la nomenclatura utópica de nuevo mundo; esto es, la nomenclatura se correspondía con la parafernalia providencial imperial ${ }^{5}$ auspiciosa y celebratoria.

Si la lengua es la compañera del Imperio, tal como anunciaba la Gramática de Nebrija en 1492, la crónica es el género que, en la Temprana Modernidad, narra el tiempo del poder y del poderoso, lo circunscribe, lo identifica y niega el pasado que no sea cristiano. La épica había asumido este rol en la Antigüedad y la Edad Media. Por esta misma condición, la crónica de Indias, sin final como toda crónica, queda abierta a la continuidad y suma futura de más episodios sucedidos en un espacio que se piensa "nuevo" y en un tiempo fundacional y promisorio. Narra lo contrario de un mundo pensado en decadencia (mundo senescit) y se posiciona frente al nativo como "el caído", el aniquilado o el conquistado, que es uno de los elementos de los que se siente obligada a dar cuenta. El género de la crónica sirve constitutivamente a la cancelación de un mundo anterior que pasará a ser, a partir del momento de escritura, un pasado prehistórico.

Luego, los cronistas indígenas y mestizos han buscado desplazar este "inicio" a tiempos anteriores al apropiarse del género discursivo y del poder simbólico que se hallaba asociado a él. Justamente, incluyeron sus relatos culturales e históricos en el molde que implicaba la narración y la crónica. En esto, se implicaron, entre otros, los cronistas Hernando de Alvarado Tezozomoc (c. 1525-c. 1610), Diego Muñoz Camargo (1629-1599), Fernando de Alva Ixtlilxóchitl (c. 1578-1650), Don Francisco de san Antón Muñón Chimalpahin Cuauhtlehuanitzin (1579-1660), Juan Buenaventura Zapata y Mendoza (c. 1620-c. 1688), Titu Cusi Yupanqui (c. 1526-1570), Inca Garcilaso de la Vega (1539-1616), Guamán Poma de Ayala (c. 1534-c. 1640) y Joan de Santa Cruz Pachacuti (fines del S. XVI-principios del S. XVII), para mencionar solo algunos cronistas mesoamericanos y de las zonas andinas.

\section{El testigo de vista}

La figura del testigo de vista es un componente importante en las crónicas de Indias, muchas de las cuales tenían, como base, las formas discursivas y retóricas de la relación legal de fechos, en la que la verdad estaba dada por "lo visto y lo vivido" por el sujeto

\footnotetext{
${ }^{4}$ Por esto, en Mito y archivo, González Echevarría esboza la idea: "el Archivo es un mito moderno basado en una forma antigua, una forma de comienzo" (González Echevarría, 1998, 51)

${ }^{5}$ Sobre el providencialismo imperial: "Si bien el providencialismo tiñe la producción historiográfica castellana desde los tiempos en los que Paulo Orosio llevó a esas tierras la concepción agustiniana de la Ciudad de Dios, será con los Reyes Católicos que este tipo de discurso llegue a su máximo esplendor.” (Hamlin, 2012, 359)
} 
del discurso. Luego, los cronistas indios y mestizos, quienes comenzaron a escribir Historia varios años después de sucedidos los hechos de Conquista y a revisar las versiones oficiales, transformaron el dispositivo del testigo de vista. Algunos sostenían que la verdad estaba dada en sus crónicas, porque ellos conocían, por relación familiar, las historias de sus antepasados, quienes sí habían presenciado y hasta padecido los hechos de primera mano. Otros, sabiendo de la importancia de la lengua para la historiografía humanística renacentista, argumentaban que sabían la verdad, porque conocían la lengua original y podían traducir fielmente las versiones indígenas antiguas de los hechos.

Pero, antes de esta transformación e, incluso, antes de la proliferación de relatos indianos marcados por la figura retórica del testigo de vista, las Historias y relatos de viaje hacían uso de otro dispositivo de verdad para lo narrado. En la alta Edad Media europea, lo verdadero era lo que habían referido los libros de autoridades y esto pervive en las crónicas de Indias, aunque en decadencia. Es así como Colón mismo buscaba, en América, lo que había leído en la Historia rerum ubique gestarum del Papa Pío II, la Imago mundo del cardenal Pierre d'Ailly, la Historia natural de Plinio el Viejo y, sobre todo, las descripciones de Oriente contenidas en los Viajes de Marco Polo. Así, el corpus colombino está marcado por la transición entre la Edad Media y el saber de la experiencia, que crecerá en reputación en la Modernidad. La carta que Colón les dirige a los Reyes apenas llega al Mar de España posiciona fuertemente su propia participación como testigo de lo vivido: "Yo vengo de las Indias con la armada que V. Al. me dieron, adonde yo pasé en treinta y tres días después que yo partí de vuestros reinos" (Colón, 2012, 299). El énfasis en la experiencia de la primera persona singular funciona como certificado de verdad de todo lo descripto. Sin embargo, hasta su muerte, Colón aseguró que había llegado y visto la costa occidental de la India. En su segundo viaje, obliga a sus compañeros de la armada real a afirmar que Cuba era Tierra Firme y no isla, porque así lo afirmaban las escrituras y las cartas náuticas consultadas hasta el momento.

Las crónicas de Indias que siguieron a las suyas, del mismo modo, dieron cuenta de esta transición entre el saber por las autoridades/los autores o saber libresco y el saber de la experiencia. Por ejemplo, Fernández de Enciso, socio de Alonso de Ojeda, competidor de Núñez de Balboa en la región del Darién y quien escribió el primer tratado geográfico que incluye a las Indias Occidentales publicado en 1519 (Suma de geografía), afirmó que los navegantes buscan: "por la mar, las tierras de que en las escrituras se hace mención" (Fenández de Enciso, 1519, fol. II). Viajeros, adelantados y escribientes formulaban discursivamente lo novedoso desde lo ya imaginado, pero, consideraban que ya se había dicho todo lo de importancia.

Sobre este punto, Mignolo (1981) entiende tal dicotomía en estos términos: la verdad de la historiografía podía estar asentada sobre la "causa eficiente" de la Historia (es decir, sobre la demonstración de sabiduría del historiador como hombre de letras) o sobre la verdad de dicto (esto es, la verdad atribuida a los hechos). En otras palabras: se trataba de la verdad atribuida al historiador por capacidad enumerar diversas citas de autoridades que su biblioteca mental había obtenido o -desde un punto de vista pragmático - por su habilidad para enumerar objetos referidos y episodios narrados. 
Mignolo afirma lo primero - la causa eficiente - basado en las propias afirmaciones de los cronistas, como el siguiente consejo de Bartolomé de las Casas, que incluye en el prólogo a su Historia de las Indias:

Tampoco conviene a todo género de personas ocuparse con tal ejercicio [la escritura de la Historia], según sentencia Metástenes, sino a varones escogidos, doctos, prudentes, filósofos, perspicacísimos, espirituales y dedicados al culto divino, como entonces eran y hoy son los sabios sacerdotes. (Casas, [1951] 1981, t. I, 6)

Pero, luego, Mignolo describe cómo, a medida que el contacto con testigos oculares y la cercanía del sujeto con los hechos y los acontecimientos comienzan, con el tiempo, a ser las únicas garantías del conocimiento y verdad entre las crónicas de Indias. Por lo tanto, plantea, será la crítica a las historias previas, escritas en su mayoría a la distancia desde la península ibérica, como las de Francisco de Gómara, lo que demuestre conocimiento histórico y verdad de los hechos referidos (Mignolo, 1981, 389).

Karl Kohut (2009) sostiene que la máxima clásica de Flavio Josefo -retomada también por Tucídides y por Isidoro de Sevilla-, que privilegia "lo visto y lo vivido", llega a los cronistas españoles y, luego, a los indianos a través de Juan Luis Vives y su intérprete o lector Pedro de Rhua -quien se expresó en cartas dirigidas al cronista Antonio de Guevara-coincide punto por punto con los criterios de verdad que se imponían los cronistas de Indias. El criterio, además, les era útil a esos hombres de poca nobleza y experiencia cortesana -es decir, de poco conocimiento y lecturas-- que la Corona española enviaba a las Indias no precisamente para crecer en abolengo ni mucho menos para fundar reinos modernos con una profunda conciencia documentalarchivística y letrada. El estilo llano, exento de ornatos y fórmulas de la retórica, plantea Kohut, se veía asociado a la verdad del testigo ocular y opuesto al escribir con elegancia y ornamentos de retórica en declaraciones paratextuales y capítulos de reflexión historiográfica de estos cronistas, lo que ejemplifica con las crónicas de Gonzalo Fernández de Oviedo, Cieza de León y Bernal Díaz del Castillo.

Beatriz Colombi, en cambio, en su estudio sobre la Brevísima de Las Casas, analiza este momento de transición con las herramientas del campo de lo legal y lo filosófico. Estos cronistas estarían, según Colombi, marcados por el pasaje de la disputatio escolástica, en la que prima la cita de autoridades como prueba de los hechos, a la indagación de testimonios, definida por Michel Foucault como el recurso novedoso que contiene la palabra de los testigos de vista. A pesar de lo esperado, la Brevísima de Las Casas no recurre a las autoridades sino a los testigos de vista, y el testimonio aquí tiene el efecto, en contextos legales, de poner, ante la vista, lo ocurrido como si se estuviese presenciando en el presente. Pero, citando nuevamente a Foucault, Colombi observa que esta cronística ya no utiliza a los autores como autoridad sino como testimonio. Esta transición de formas de autentificación del saber otorga paulatinamente más valor a lo dicho por los autores que refieren y narran lo que han visto recientemente y que son citados como testigos de primera mano. Los efectos de lectura de presencialidad y proximidad: "se refuerza[n] con el registro, también sensible, del palpar" (Colombi, 2013, 93). 
El yo del testigo, a pesar de convencionalmente estar asociado a efectos de identificación, claridad y verdad, es discursivamente diverso, múltiple y heterogéneo, como no podía ser de otra manera. Considero que las preguntas que deben hacerse sobre este punto para no caer en la trampa de este recurso y sus efectos de verdad deberían ser: ¿qué es lo que ve el testigo de vista?, para poder responder así a: ¿cuál es su verdad? y, entre otras: ¿quién o quiénes son el yo que dice "he visto y he vivido"? Las respuestas posibles son, sin duda, complejas, pero creo que son inevitables para no caer en definiciones redundantes y tautológicas, en las que muchas veces cae la historiografía involuntariamente. El tercer interrogante se pregunta por los límites del sujeto. Por ejemplo, la Carta de Pero Vaz de Caminha a El-Rei D. Manuel sobre o achamento do Brasil, escrita en 1500, refiere la llegada a las tierras de Vera Cruz en Brasil de la flota portuguesa de Pedro Álvares Cabral. El sujeto enunciador se traslada de la primera persona singular a la tercera singular para referir las acciones del capitán a una decidida y recurrente primera persona plural:

Neste dia, a horas de véspera, houvemos vista de terra! Primeiramente dum grande monte, mui alto e redondo; e doutras serras mais baixas ao sul dele; e de terra chã, com grandes arvoredos: ao monte alto o capitão pôs nome - o Monte Pascoal e à terra - a Terra da Vera Cruz. (Vaz de Caminha, 2007, 1)

Ver y descubrir, enunciados desde el plural, parecen concentrarse, más que en asegurar la verdad de lo visto, vivido y referido, en certificar a los sujetos de tal visión; más que otorgar mérito y fama a un héroe, el plural parece atribuir un triunfo a lo colectivo restar o compartir el mérito del capitán en alguna medida.

Luego, otros ejemplos también son recurrentes para dar cuenta de un yo testigo enunciador complejo, como el de los textos de Álvar Núñez Cabeza de Vaca publicados en 1555, la Relación (conocida como Naufragios) y Comentarios. La primera es resultado de una serie de hipotextos escritos por los cuatro sobrevivientes de la armada de Pánfilo de Narváez en la Florida ante los tribunales reales en los que narraron su peregrinar y cautiverio de ocho años entre los nativos que habitaban el sur de lo que hoy es Estados Unidos. Comentarios es el escrito de su secretario/escribano Pero Hernández sobre el viaje y gobernación de Cabeza de Vaca en el Río de la Plata y Paraguay. Su autoría es doble, de Álvar Núñez y de Hernández al mismo tiempo, y su hipotexto también es un texto legal escrito por el primero para su defensa ante las numerosas acusaciones recibidas por su mal desempeño.

Por su parte, la misma Brevísima relación de Bartolomé de las Casas -redactada originalmente en 1542 y publicada en 1552-- edifica un complejo particular de testigos y testimonios de los hechos. Con palabras de Santa Arias:

[Sobre una escena] el narrador describe la crueldad de los eventos con los detalles que le ofrece la memoria como armas de guerra que van a despertar el pathos del oyente/lector. Si bien sabemos que el narrador no presenció este evento, él se coloca como testigo ante la ejecución de los amerindios: "Yo vide todas las cosas arriba dichas y muchas otras infinitas." (Arias, 2000, 76) 
Consciente de que el testigo de vista es una construcción retórica, Las Casas lo utiliza con soltura para certificar las destrucciones de las conquistas y testimoniar acerca de un mundo perdido que los frailes, con ayuda de la Corona, deberán reconstruir.

Aquí, tampoco podríamos dejar de mencionar la Historia general de las cosas de Nueva España de fray Bernardino de Sahagún, proyecto monumental editado y coordinado por el fraile, pero cuyo autor/autores son difícilmente delimitables. Escrita en español, náhuatl y algunos fragmentos en latín, la Historia puso en texto las versiones de la conquista y de la cultura mexica de descendientes de las élites indígenas transcriptas y recopiladas por discípulos indígenas de Sahagún. Además, el códice tiene alrededor de 1800 imágenes realizadas por indígenas tlacuilos. Para nuestro interés, la obra se sostiene sobre la idea de la multiplicidad de verdades y de puntos de vista diversos multiculturales, multilingües y multisemióticos de los testigos de los hechos y de sus testimonios. Quizás, por esto mismo, ciertamente la obra de Sahagún no pudo ser leída en la época en que fue producida y cayó en el olvido hasta el siglo XIX, y, completa, en el XX.

\section{Mundo de conocidas y novedosas maravillas}

Dado que el testigo de vista es una figura retórica, aquello que ve el sujeto enunciador -aunque determinado y transformado por el contexto transatlánticotambién se encuentra codificado. Viajeros, adelantados y escribientes percibían lo maravilloso y lo novedoso ya codificado discursivamente, es decir, ya imaginado, escrito y divulgado. Por esto, Juan Gil, conocido editor del corpus colombino, atribuyó un rol primordial a la hipótesis asiática de Colón en su elaboración de las visiones europeas de las maravillas de las Indias. En esta misma línea, Stephen Greenblatt, en Marvelous Possessions (1991), afirma que las representaciones europeas del Nuevo Mundo sólo nos hablan acerca de los conocimientos europeos. Sin embargo, en lo que exponemos a continuación, nos permitimos poner en duda tales afirmaciones.

Cualquier relevamiento en las crónicas de Indias demuestra que la búsqueda de lo maravilloso no es solamente el deseo de hallar lo que los libros y los autores ya han dicho acerca de ello. Más exactamente, por la puerta de lo maravilloso, probablemente ingrese lo diverso, en confluencia de representaciones provenientes de heterogeneidades culturales. En la primera etapa de simbolización del encuentro por medio de elementos maravillosos, la figura retórica y sintáctica que los caracteriza es el oxímoron o la paradoja de dos términos antitéticos puestos a jugar en relación. Así, por ejemplo, Américo Vespucci manifiesta en sus cartas de principios del siglo XVI que se sorprende porque, aproximándose a las costas del Nuevo Mundo, todo el mar es dulce, lo que constituye un oxímoron de trascendencia inobjetable. Además, se asombra de que la zona tórrida, comprendida entre los dos trópicos sea -sin inconvenientes- del todo habitable, lo que contradice las afirmaciones de los filósofos antiguos. También Fernández de Enciso se maravilla por lo mismo.

Otros oxímoros como los mencionados, entre muchos otros, son la juventud eterna de los humanos y de la naturaleza, la variedad infinita de colores y formas, los hombres 
monstruosos, la monstruosidad de los hombres sodomitas y las mujeres nobles entregadas al placer como si fueran prostitutas. Del mismo modo, Juan Díaz (Itinerario de larmata del Re catholico in India uerso la Isola de Iuchatan, 1526) y Fernández de Enciso se maravillaban por las noticias acerca de la existencia de los "hombres como nosotros". Con este sintagma, el primero se refiere a hombres con carabelas, espadas y rodelas. El segundo, en cambio, a gente que lee, tiene libros y escribe. La primera edición del manuscrito de la crónica escrita por Antonio Pigafetta (Le voyage et nauigation, 1525) es un resumen traducido al francés y publicado en 1525. Tiene anotaciones al margen que, como un índice práctico y transversal, indican, al lector, específica y constantemente los párrafos que contienen descripciones de maravillas: como los famosos gigantes de la Patagonia, el demonio Setebos que habría estado ayudando a los gigantes, las islas infortunadas, perlas del tamaño de huevos, entre otros. Es cierto que el oxímoron compite con la hipérbole, con los contrastes y la antítesis, pero reina -por sobre ellos- el efecto de choque semántico, asombro e inquietud. Estas figuras serán también las que caracterizarán lo Real Maravilloso de la literatura del Boom Latinoamericano. Alejo Carpentier fijó una definición para este género en la que reconoció la herencia discursiva de las crónicas de Indias, por ejemplo, en El reino de este mundo (1949).

El oxímoron, por otra parte, es una figura del pensamiento. La palabra, de origen griego, etimológicamente significa "locura extrema" o "aguda". En este sentido, justamente La nave de los locos o de los necios de Sebastian Brant había sido publicada y editada una y otra vez en el período al que nos estamos refiriendo. La primera edición apareció en 1494 en Basilea; con muy pocos meses de diferencia respecto de la tan mentada carta de Colón, que se dio a conocer en latín en Europa -con ilustraciones muy conocidas - que también fue publicada en Basilea, pero en abril de 1493 y dirigida al tesorero real Gabriel Sánchez. Volviendo a Brant, su obra contiene tres capítulos que me interesan para esta investigación: "De la experiencia de todos los países", "Del encontrar un tesoro" y "La nave del país de las maravillas". En ellos, Brant concluye que no es nada sorprendente que el deseo de viajar cada vez más lejos lleve a los hombres a encontrar maravillas, como sirenas y delfines. La necedad del stulto estaría, de esta manera, en arriesgarse en estos viajes. Para Brant y para la época, todo lo que implique aventura, riesgo y -sobre todo- distancia de un centro tranquilizador solía estar asociado, necesariamente, con los valores de la locura, la necedad y el absurdo. En este punto, quiero plantear cómo lo maravilloso, aunque podía ser definido de antemano en los libros, también escapa lo más lejos posible de un centro conocido y es el que habilita el ingreso de lo diverso.

En Fernández de Enciso, por ejemplo -como en Colón-, las tierras del oro siempre se encuentran en la próxima isla, en el interior del continente o en poder de indios guerreros. La búsqueda del oro lleva a estos navegantes a desplazarse continuamente y a describir los signos de la riqueza. De este modo, la esperanza de hallar lo maravilloso, que está siempre ausente, obliga a narrar lo visto como signos. Más aún, este deseo promueve la escritura de documentos y la publicación de libros que narran lo nunca antes visto. Es claro que los textos señalan la localización de lo maravilloso en un 
interior cerrado o en un exterior muy apartado, en los espacios muy abiertos o en los muy cerrados. Suelen imaginarlo como el paraíso, tan alejado como lo celestial hacia el exterior, pero resguardado, por momentos, en un interior como el infierno y por criaturas, muchas veces, infernales o monstruosas. El Nuevo Mundo, aislado por el Océano Atlántico, ofreció una oportunidad única para esta pulsión. Más aún, el haber descubierto que se trataba de un continente nuevo y no de un grupo de islas desconocidas ni del remoto Oriente redundó en que se acentuaran las hipotéticas localizaciones interiores de lo maravilloso. Fernández de Enciso, que recorrió parte de la costa de Centroamérica, es claro en este sentido. Los últimos capítulos sobre las Indias occidentales de su Summa de geographia, repiten incansablemente: en aquellas montañas, selvas, nacientes de río, pueblos de indios, entre otros muchos, se encontrará oro.

Michel da Cúneo, en su De novitatibus insularum occeani de 1495, refiere una escena sobre algo nunca visto. En el segundo viaje de Colón, en una ocasión, aparecieron sobre una barca unos hombres castrados. Sus heridas aún estaban frescas, recién cerradas. Los navegantes inmediatamente "comprenden" que se trata de un grupo de cautivos de los indios caníbales. Piensan que estos últimos apresan a sus enemigos y comen su sexo como parte de sus rituales antropofágicos. Américo Vespucci, por su parte, también relata en Mundus Novus una escena similar: luego de un combate, en una canoa encuentran a cuatro jóvenes castrados recientemente. Pero, en este caso, su autor explica que, por lo que estos indios dijeron por señas, los cautivos habían sido castrados, porque el ritual señalaba que esto era lo que previamente debía hacerse antes del acto de antropofagia. De esta manera, estos hombres feroces, para unos, se alimentan de los hombres, pero no de su sexo; en cambio, para otros, los caníbales se alimentan de sexos y desperdician el resto de los cuerpos. En este punto, me pregunto qué es lo que los ha llevado al encuentro con lo extraño y con lo diferente; es decir, lo sorprendente, la alteridad, lo incomprensible que, finalmente, transforma el discurso. En primer lugar, los maravilla el haber encontrado signos de los antropófagos, esos seres que - de manera paradójica - en la tradición clásica eran considerados seres humanos, pero que -como animales- no discernían los límites definidos por la fe cristiana entre las costumbres humanas y las bestiales. Ahora bien, el placer de lo maravilloso, de describir lo novedoso, lleva a Da Cúneo y a Vespucci a dar cuenta también de la práctica nativa de la castración de indios cautivos de una manera ambivalente y múltiple. Esto transforma de manera acentuada el mito tradicional de los antropófagos que vivían más allá de la región de Scitia. Ya en Colón, las visiones de Oriente de los reinos del Gran Khan, la expectativa de hallar antropófagos en los confines y las heridas casi mortales observadas en los cuerpos de los nativos habían confluido para iniciar la nueva tradición de los indios caníbales del Nuevo Mundo, concepción heterogénea en sí misma. Los antropófagos descriptos en la tradición clásica vivían totalmente aislados en cuevas. En el Nuevo Mundo, los caníbales eran reconocidos por signos inquietantes y sorprendentes en los cuerpos de las tribus nativas de las Indias. Las marcas eran definitivamente observadas por los narradores de los primeros encuentros. 
Lo maravilloso y sorprendente tiene la función de aunar, como en semiosis del conocimiento, algo nuevo y algo conocido a la vez que, de manera forzosa, se sincretizan y dialogan de forma, por lo menos, poco armónica. En los elementos maravillosos, importantes movilizadores de expediciones y de inversiones imperiales en el Nuevo Mundo, confluyen no sólo varias tradiciones occidentales sino, también, elementos propiamente indígenas, registros y observaciones agudas acerca de sus costumbres. Estas visiones de lo paradójico, de lo sorprendente y, también, de lo deseado no son necesariamente precisas, pero sí son algo nuevo y diferente que colisiona ante la mirada de los recién llegados y junto con ella. Ofrecen algo transformado y que transforma los discursos y las culturas de unos y de otros en una relación e intercambio en tensión.

Alfredo Cordiviola, en Espectros da geografía colonial. Uma topología da ocidentalizaçao da América, sostiene una hipótesis interesante a lo largo del libro: las maravillas que describen América en la cronística de los conquistadores e historiadores --“antecipaçoes latentes", "reverberações míticas", "projeções imaginárias", etc."convalidam e definem a ocidentalização do continente americano" (Cordiviola, 2014, 18). Contribuyen a los modos de percepção que precisamente definem esse mundo enquanto novidade e enquanto periferia. Modelada por esas lógicas, a modernidade se constitui como uma grande máquina produtora de espectros. Como expusimos más arriba, las maravillas y lugares imaginados esperados para la geografía americana son, finalmente, importantes movilizadores de expediciones y de inversiones imperiales en el Nuevo Mundo, lo que lleva -propone Cordiviola - a que sean importantes elementos administradores de la occidentalización del continente.

Algunos de estos "espectros de la imaginación" que han sido proyectados son, por ejemplo, las islas fortunadas de Brasil y San Brandam, las que aparecen en numerosos mapas y portulanos desde el siglo XIII en adelante, como en la célebre compilación de mapas del flamenco Abraham Ortelius, el Theatrum orbis terrarum. Por su forma de islas, concentran el deseo del espacio enclaustrado, en donde, por su aislamiento, podrían ocurrir eventos extraordinarios. En esta misma tradición, se encuentra la misma Atlántida, ficción de una isla del pasado siempre desaparecida en el presente y, por esto, eternamente buscada. Cronistas de Indias como Las Casas, López de Gómara, Agustín de Zárate, Sarmiento de Gamboa, fray Gregorio García, Diego Andrés Rocha asociaban el Nuevo Mundo con lo predicado de antiguo sobre la Atlántida, a veces, como isla originaria de sus pobladores.

Así, también, el Dorado - relato legendario que los propios nativos sudamericanos alimentaron-- se consagró como el lugar que todos querían descubrir. La más deseada por las expediciones americanas entre las ciudades apócrifas y los reinos encantados era tanto un ritual que practicaban unos caciques y en el que abundaba el oro en sus diversas formas, como un lugar, un lago, una ciudad, un reino o una provincia. Representaba, además, el más grande desafío que los conquistadores en América podían plantearse. Como los animales extraños y los humanos monstruosos, lo que no existe, pero podría llegar a existir, como el Dorado, son, además de deseos proyectados, figuraciones de las disputas diversas por las posesiones ultramarinas. De tradiciones 
mestizas, europeas y amerindias, Cíbola y Quivira, pero también Marata, Acus y Tontonteac, fueron reino y ciudades buscadas en Norteamérica. El mito, de origen medieval portugués, refiere que siete obispos que huyeron de los árabes y conquistaron la península ibérica, fundaron luego siete ciudades en una gran isla lejana, relato que de acuerdo con Enrique de Gandía (1929) y Beatriz Pastor (1983)—pudo haberse fusionado con el de las siete tribus nahuas de Chicomoztot. Pero, además, los amerindios -identificados y tipificados por Beatriz Pastor como- guías y cautivos indígenas creadores de fábulas avivaban en sus descripciones estos relatos para saciar el deseo de los propios conquistadores.

El mito de Paititi emerge con posterioridad a los primeros años posteriores a la conquista del Perú y refiere a una colonia escogida por los incas para huir y refugiarse del alcance de los invasores; por esto es, también, un símbolo de restauración y retorno. El informe del padre Andrés López, por ejemplo, describe que el sitio está habitado por hombres blancos, belicosos, acumuladores de riquezas y metales preciosos. Los documentos lo describen como amenaza, es decir, como posible foco de insurgencias desde donde los incas podrían iniciar la recuperación del poder perdido. Los relatos sobre el Rey Blanco y la Sierra de la Plata, muchas de las cuales referían los pueblos guaraníes y otros cercanos a la gran cuenca del Río Paraná, alimentan también el mito de Paititi. Los Comentarios (1555) de Álvar Núñez Cabeza de Vaca, por ejemplo, refieren cómo este mito del Rey Blanco de los nativos de Paraguay lo llevó a incursionar -infructuosamente-- la cuenca del Mato Grosso, última esperanza, para el Adelantado, de ofrecer un mérito y un servicio a la Corona española en medio de sus decisiones desacertadas como gobernador de la región. Cordiviola (2014, 182) considera que las tres apariciones de Paititi (producto de las exploraciones de Diego Alemán, Maldonado y del testimonio del Padre López) se extienden entre 1560 y 1570, es decir, en los años decisivos para la afirmación del dominio español en América del Sur. Además de la de López, deben tenerse en cuenta el Memorial de la jornada de los Mojos y descubrimiento de la tierra de los llanos (1564) de Diego Alemán y la Relación verdadera del discurso y subceso de la jornada y descubrimiento (1567) escrita por un acompañante anónimo de Juan Álvarez Maldonado, entre otros.

Por su parte, la existencia del Paraíso en la Tierra pervivía todavía en tiempos coloniales, pero su localización era punto de controversias. Ya Cristóbal Colón había referido, en su tercer viaje a las Indias, que había hallado la entrada a tal sitio santo en la desembocadura de un gran río en una costa hallada al sur de las Antillas. Luego, Bartolomé de las Casas reescribe estas páginas en su Historia de las Indias y extiende la fundamentación original basada en autoridades con más citas de autoridades. Sin embargo, Paraíso en el Nuevo Mundo de León Pinelo es la obra insoslayable sobre este tema. Sobre este tema, estamos de acuerdo con Arturo Roig, para quien Pinelo pretende: "incorporar al continente americano dentro de la Historia Mundial; valorarlo frente a los otros continentes al asignarle el cumplimiento de un momento ontológico dentro de aquella Historia y, por último, justificar la integración de América a la Corona imperial española, pero en un pie de igualdad con las otras regiones que la integran." (Roig, 1986, 173) 
Por último, Cordiviola enumera la Ciudad de los Césares en esta tradición. Ubicada en la Patagonia del Cono Sur americano y dado que las naciones-Estado modernas independentistas de esta región negaron cualquier prestigio asociado a lo nativo, esta ciudad mítica no podía imaginarse habitada por indígenas. En cambio, se pensó que sus habitantes eran blancos, españoles y católicos que, rodeados por montañas y desiertos dominados por los indígenas a los que cristianizaban fácilmente, habían decidido aislarse de la colonia y del virreinato español. El informe "Derrotero de un viaje desde Buenos Aires a los Césares, por el Tandil y el Volcán, rumbo del sud-oeste", fechado en 1707 y atribuido a Silvestre Antonio de Roxas, menciona que sus habitantes sólo ejercían algún tipo de comercio con los indios llamados Césares. Pacíficos y corpulentos, cazaban guanacos y disponían de abundante plata. Algunas expediciones pocos años después - la de Diego de Rojas y la de Juan de Jufré--, algunas otras en el siglo siguiente - la del gobernador Hernandarias de Saavedra y la de Jerónimo de Saavedra-y las del siglo XVII -como la del jesuita Nicolás Mascardi, guiado por la Historia General del Reyno de Chile de Diego de Rosales-solo se decepcionaron en la búsqueda. Muchos de los episodios fueron referidos en la "Carta del Padre jesuita José Cardiel, 11 de agosto de 1746" y otros por Pedro Lozano en Diario de un viage a la costa de la mar magallánica (1745) por Thomas Falkner -inglés al servicio de la Corona española-- en su Derrotero (1760) e Ignacio Pinuer en la Relación de las noticias adquiridas sobre una ciudad grande de españoles, que hay entre los indios, al sud de Valdivia, e incógnita hasta el presente (1774). Todos ellos -algunos más inexactos y otros, como Falkner, con mucha precisión-- sustentan su relato sobre la idealización de los primeros años de la Conquista americana, quizás atribuyendo a ese tiempo el origen prestigioso de la colonización organizada en el territorio y la necesidad de "mapearlo" y controlarlo frente a la amenaza inglesa. De hecho, en 1764, James Burgh publica An Account of the first Settlement, Laws, Forms of Government and Police of the Cesares: a People of South America, in nine Letters, en donde la Ciudad de los Césares, descripta por uno de sus habitantes, estaba situada en algún lugar no identificado de Chubut, cuya capital tenía del nombre de Salem, todos sus habitantes eran protestantes y la ciudad había sido fundada en el siglo anterior por náufragos holandeses, tal como lo investigó Cordiviola en su libro.

\section{Testimonios de un mundo inquietante}

Pero, llegados a este punto, es necesario detenernos para definir los límites de lo maravilloso según lo entendía la época de transición entre la Edad Media y el Renacimiento o Primera Modernidad occidental - transatlántica en particular. Jacques le Goff, en Lo maravilloso y lo cotidiano en el Occidente medieval (1984), define lo maravilloso, tanto como lo mágico y lo milagroso, como lo sobrenatural que sorprende. Ahora bien, observamos que lo sobrenatural puede asumir las formas de lo contranatural en algunas ocasiones, ya que, también según Le Goff, lo maravilloso, esencialmente: "representa un peligro para la comunidad sagrada" (Le Goff, 1984, 175). Es decir, lo sobrenatural se ve asociado en sus márgenes a lo antinatural, se piensa contrario al 
orden diseñado por y en la naturaleza. Entendemos que, fundamentalmente, lo sobrenatural es lo que asume una dirección inesperada y potencialmente infinita, creciente, en aumento latente, hasta llegar, incluso, a transformarse en contranatural, es decir, amenazante y desestabilizador si no es controlado. Los espacios del desierto, el bosque y la selva, para los hombres del Occidente medieval eran lugares de soledad según proponen los libros de Jacques le Goff. Y las crónicas de Indias identifican a América con esos espacios de soledad, es decir, con lugares de lo rus o de lo salvaje y sobrenatural, que se encuentra, por lo tanto, en los márgenes de la actividad humana.

Si pensamos en algunos ejemplos de lo maravilloso indiano y, por unos momentos, nos imaginamos como actores de los episodios que narran el encuentro con estos fenómenos, esta concepción asociada a lo perturbador que desprendemos de las definiciones de Le Goff se ajusta a la perfección: el mar dulce, la habitabilidad de la zona tórrida, la juventud eterna, --para aquella época-los sodomitas y las nobles mujeres licenciosas, los hombres que son tal "como nosotros" en el más allá, los hombres castrados, los caníbales, los gigantes patagones, la Atlántida --utópica y de gran perfección urbana--, las ciudades ideales y las de gran riqueza como el Dorado, Cíbola, Quivira, Ciudad de los Césares, Paititi, el Paraíso Terrenal y los infiernos en la Tierra, entre muchos otros, provocan tanto espanto como admiración y despiertan o proyectan deseos.

Siguiendo a Le Goff, observamos que, en los siglos XII y XIII, lo sobrenatural occidental solía ser clasificado de acuerdo con tres dominios diferentes: mirabile, magicus o miraculosus. Ahora bien, en lo maravilloso cristiano, en el milagro y en lo mágico, hay un autor, que siempre es el dios o el demonio cristianos. Así lo clarifica Jacques le Goff:

Mirabilis: es nuestro maravilloso con sus orígenes precristianos. [...] Magicus: es lo sobre natural maléfico, lo sobrenatural satánico. [...] Lo sobrenatural propiamente cristiano, lo que se podría llamar justamente lo maravilloso cristiano, es lo que se desprende de lo miraculosus [...] tenía la tendencia a hacer desvanecer lo maravilloso. Una de las características de lo maravilloso es, desde luego, el hecho de ser producido por fuerzas o por seres sobrenaturales, que son precisamente múltiples. [...] Ahora bien, en lo maravilloso cristiano y en el milagro hay un autor, pero un único autor que es Dios. (Le Goff, 1984, 14 y 15)

Los hombres de la Edad Media tardía esperaban que les sucedieran acontecimientos milagrosos o aquellos mágicos que tramaba Satán. Para ellos, era previsible que esos autores "escribieran" en la naturaleza y en la Tierra ciertos fenómenos sorprendentes y que compitiesen por los hombres mismos.

Pero un resto de lo maravilloso se les aparecía imprevistamente y sin racionalidad, es decir, sin autor y fuera o ajeno al control. Más aún, creemos, en la lejanía del Nuevo Mundo, los hombres occidentales esperaban que lo maravilloso se les multiplicara ante sus ojos. La anomalía, la singularidad, la falta de control y la no repetibilidad sobrepasaban los límites de lo conocido y de "lo natural", y desconcertaban. Por esto, diversos cronistas escritores de historias naturales de las Indias, como Gonzalo Fernández de Oviedo (Sumario de la natural historia de las Indias, 1526), José de 
Acosta (Historia natural y moral de las Indias, 1590) y Francisco Hernández (Quatro libros de la naturaleza, y virtudes de las plantas, y animales que están recevidos en el uso de medicina de la Nueva España, 1615), entre otros, hicieron grandes esfuerzos por capturar lo maravilloso indiano y lo transmarítimo en alguno de los polos, el divino o el demoníaco. Todos los cronistas de Indias, en alguna ocasión, se recuerdan y le recuerdan al lector que la Providencia Divina dispuso, frente a ellos, el conocimiento de las maravillas del Nuevo Mundo. Además, contienen el mensaje de que sería necesario que la Corona hiciera algo con lo que la Providencia les ofreció en el mundo nuevo o Nuevo Mundo.

Ya hemos mencionado muchas funciones, en el imaginario cultural y en lo discursivo, de lo maravilloso. Le Goff (1984) enumera otras más: está profundamente integrado en esa búsqueda de la identidad individual y colectiva del caballero idealizado; imaginariamente suele compensar la escasez y la infelicidad en la Tierra; representa, por momentos, una oposición a la ideología cristiana (es decir, lo maravilloso como cierta resistencia cultural a la creciente visión cristiana antropomórfica de Dios) en un universo más animalista, mineralógico, vegetal); constituye un repudio del maniqueísmo cristiano; entre otras. Desde la antropología, Hugo Bauzá (2005) define lo mítico en particular como realidad trascendente, una transrealidad, a un ámbito numinoso (númen "espíritu"), realidad a la que no se tiene acceso mediante el pensamiento racional y el ámbito misterioso donde habita lo inefable. Además, para Bauzá, el mito nos orienta sobre mundos y perspectivas exóticos: el reino de los sueños, el de las fantasías, el de las pulsiones del inconsciente, el de las ensoñaciones más variadas, también, las visiones provocadas por alucinógenos. Es una forma particular de lenguaje, por eso, ningún mito debe ser tratado en forma aislada sino que es en el conjunto donde adquiere su verdadera semanticidad.

Luego, otros autores como Stephen Greenblatt (1991) y Beatriz Pastor (1983) consideran las funciones cognitivas y de anticipación que proveen lo maravilloso y el discurso mitificador arrojado sobre lo latente desconocido americano y como primer acercamiento por medio de un proceso de identificación. Pero, también, destacan cómo lo maravilloso constituye el discurso de la posesión, que carga con todo lo imaginado, deseado y prometido, y cómo, por esto, la descripción maravillosa tiene la función de erigir una diferencia absoluta donde se da el más profundo parecido (la proyección del otro de uno mismo, etc.). No solamente esto, la maravilla y la descripción utópica otorgaban verosimilitud a la escritura sobre el Más allá. Sobre él, se esperaban las características de las Antípodas, tal como analizaron Paolo Vignolo (2009) y Carolina Martínez (2019). Del mismo modo, los cuestionarios del Consejo de Indias ordenaban registrar todo lo notable que en las colonias de ultramar se pudiera registrar. Ya en tiempos avanzados de la colonia en América, criollos, mestizos y españoles olvidados allí por la Corona en el otorgamiento de reconocimiento, dineros y hasta de destinos registraron una memoria de lo notable para revertir su situación de abandono, tal como estudió Elena Altuna (2009). Más aún, también deberá prestarse atención a las transformaciones de estos procesos de mitificación en la zona de contacto, es decir, a sus mutaciones y perturbaciones a nivel simbólico en contacto con los imaginarios 
míticos y utópicos amerindios, y ante su reacción y agencia frente los avances de la colonización.

$\mathrm{Si}$, como propone Stephen Greenblatt (1991), la maravilla o mirabilia en crónicas del Nuevo Mundo, habilitaba el avance, conquista y posesión de los espacios de ultramar, consideramos que, por su parte, las utopías -como función en el discurso sobre las Indias- serán el elemento que organice, a nivel simbólico, ya no el avance conquistador sino la colonización directamente, cristiana e imperial. Así, el De único vocationis modo de Bartolomé de las Casas, las Ordenanzas de Vasco de Quiroga, las epístolas entre frailes tanto de las redes españolas como las portuguesas, y todas las propuestas, métodos y objetos que sirvieron a la evangelización, entre las cuales, la orden franciscana en el Norte y la jesuita en el Sur tuvieron un papel prominente, responden a esta función colonizadora de la utopía en América de la conversión. Con posterioridad, la literatura latinoamericana se apropiará de lo maravilloso exógeno -en las formas de lo real maravilloso y del realismo mágico-y la ensayística, del sintagma, anhelo y sentir conocido como la Utopía de América, pues ambos les servirán como componentes basales para la construcción de la identidad latinoamericana y atizadores de su cohesión. De esta manera, las crónicas de Indias dieron testimonio de un mundo que percibían sólo como ruinas, por un lado, y, por el otro, contribuyeron profundamente con la construcción de un discurso y una identidad nueva heterogénea, dolorosa y esperanzadora.

\section{Referencias bibliográficas}

Agamben, Giorgio (2019). Lo que resta de Auschwitz. (E. Castro, Trad.) Buenos Aires: Adriana Hidalgo.

AltunA, Elena (2009). "Contra toda mudanza: memoria de 'lo notable'”. En E. Altuna, Retórica del desagravio (págs. 47-71). Salta: CEPIHA.

Arias, Santa (2000). Retórica, Historia y Polémica. Bartolomé de las Casas y la tradición intelectual renacentista. New York: Oxford University Press of America.

BAUZÁ, Hugo (2005). Qué es un mito. Buenos Aires: FCE.

CARPEnTIER, Alejo (1949). El reino de este mundo. La Habana: Alfred A. Knopf.

CASAS, Bartolomé de las Casas ([1951] 1981). Historia de las Indias. (A. Millares Carlo, Ed.) México: FCE.

Chang Rodríguez, Raquel (1982). "La transgresión de la picaresca en los Infortunios". En R. R. Chang, Violencia y subversión en la prosa colonial hispanoamericana. Madrid: José Porrúa Turanzas.

ColombI, Beatriz (2013). "La Brevísima relación de la destrucción de las Indias de fray Bartolomé de las Casas en el eje de las controversias". Zama, 5, 91-102.

Colón, Cristóbal (2012). Diario, cartas y relaciones. (V. Añón, \& V. M. Teglia, Edits.) Buenos Aires: Corregidor.

CORDIVIOLA, Alfredo (2014). Espectros da geografía colonial. Recife: Ed. Universitária da UFPE.

FENÁNDEZ DE ENCISO, Martín (1519). Summa de geographía. Sevilla: Juan Cromberger. 
FunES, L. (2008). "Elemenos para una poética del relato histórico". En A. Arizaleta, Poétique de la chronique: L'écriture des textes historiographiques au Moyen Âge (págs. 241-273). Toulouse: Université de Toulouse-Le Mirail.

GANDíA, Enrique de (1929). Historia crítica de los mitos de la conquista americana. Buenos Aires: Juan Roldán y compañía.

GONZÁLEZ ECHEVARRÍA, Roberto (1984). "Humanismo, retórica y las crónicas de la conquista”. En R. González Echevarría, Historia y ficción en la narrativa hispanoamericana (págs. 149-166). Caracas: Monte Ávila.

(1998). Mito y archivo. México: FCE.

Greenblatt, Stephen (1991). Marvellous Posessions. The Wonder of the New World. NY: Oxford University Press.

HAmLIn, Cinthia M. (2012). “'Pareció ser cosa hecha por mano de la divina providencia': el discurso providencialista, un caso de continuidad y desvío desde la crónica real a la indiana". Revista de poética medieval, 359-375.

Huaman Poma de Ayala, Felipe (2015). Nueva crónica y buen gobierno (Vol. I. Versión paleográfica del códice original). (C. Araníbar Zerpa, Ed.) Lima: Biblioteca Nacional del Perú.

KoHUT, Karl (2009). "Las primeras crónicas de Indias y la teoría historiográfica". Colonial Latin American Review, 18(2), 153-187.

LE GofF, Jacques (1984). Lo maravilloso y lo cotidiano en el Occidente medieval. Barcelona: Gedisa.

MARTíneZ, Carolina (2019). Mundos perfectos y extraños en los confines del Orbis Terrarum. Buenos Aires: Miño y Dávila.

Mignolo, Walter (1981). "El metatexto historiográfico y la historiografía indiana". Modern Language Notes, 96(2), 358-402.

Mignolo, Walter (1982). "Cartas, crónicas y relaciones del descubrimiento y la conquista”. En L. Íñigo Madrigal, Historia de la literatura hispanoamericana (Vol. I, págs. 57-102). Madrid: Cátedra.

PASTOR, Beatriz (1983). Discurso narrativo de la conquista de América. La Habana: Casa de la Américas.

RoIG, Arturo A. (1986). "La 'inversión de la filosofía de la historia' en el pensamiento latinoamericano". Revista de Filosofía y Teoría política, 26-27, 170-174.

Vaz de Caminha, Pero (2007). A carta de Pero Vaz de Caminha. (I. Soler, Ed., \& I. Soler, Trad.) São Paulo: Fundação Biblioteca Nacional.

Vignolo, Paolo (2009). Cannibali, giganti e selvaggi, Creature mostruose del Nuovo Mondo. Milan: Mondadori.

WHITE, Hayden (1992). "El valor de la narrativa en la representación de la realidad". En H. White, El contenido de la forma (págs. 17-40). Barcelona-Buenos Aires: Editorial Paidós. 